\title{
Description of an alternative method for optimal and comfortable two-handed face mask ventilation: the transverse mandibular technique
}

\author{
Francois Lemay ${ }^{1,2^{*}}$ (D) and Jeremy Cooper ${ }^{3}$
}

To the Editor,

Recent recommendations stress the importance of avoiding aerosolization while attempting rescue facemask ventilation (FMV) with COVID-19 patients [1]. In addition, major difficult airway algorithms already highlight the importance of oxygenation rather than intubation, and many include best attempts at facemask ventilation (FMV) while progressing in cannot intubate cannot oxygenate situations [2, 3].

Best attempt at FMV may be challenging, and two major techniques have been so far well described for two-handed FMV: the double CE-grip and the thenar eminence techniques, or VE-grip [4]. We would like to share an alternative technique that provides good FMV conditions through improved jaw thrust, mask seal and ergonomic comfort. We would describe this technique as the transverse mandibular technique (Fig. 1), for which we have not found any description in the literature. We believe it is already performed by some clinicians and that its use and potential benefits should be discussed.

In this technique, emphasis is on mandibular advancement and mask seal. Fingers of both hands (mainly through the index and middle fingers) are placed transversally under the angle of the mandible to achieve an optimal jaw thrust. The thumbs are positioned transversely over the middle of a standard facemask on both sides, pushing down to achieve proper facial seal.

We believe the transverse mandibular technique has some advantages:

1. The strongest fingers in both hands are used to make an appropriate jaw thrust.

2. The thumb grip is potentially less tiring. In other techniques, lateral pressure must be used with the thumbs, which can be difficult especially in smaller hands.

3. The wrists are kept straight over a wide range of table height. This is relevant as the hands have been shown to have a stronger grip with the wrists in a neutral position [5].

4. The position of the hands fits a wide range of facemasks and patients' sizes and can be used in both adult and paediatric patients.

5. It can be performed standing in front of the patient, which can be useful in critical situations when many practitioners are managing the airway.

* Correspondence: francois.lemay.5@ulaval.ca

'Département d'anesthésiologie et de soins intensifs, Université Laval,

Québec, Canada

${ }^{2}$ Centre Hospitalier Universitaire de Québec, Hôtel-Dieu de Québec, Québec, Canada

Full list of author information is available at the end of the article 


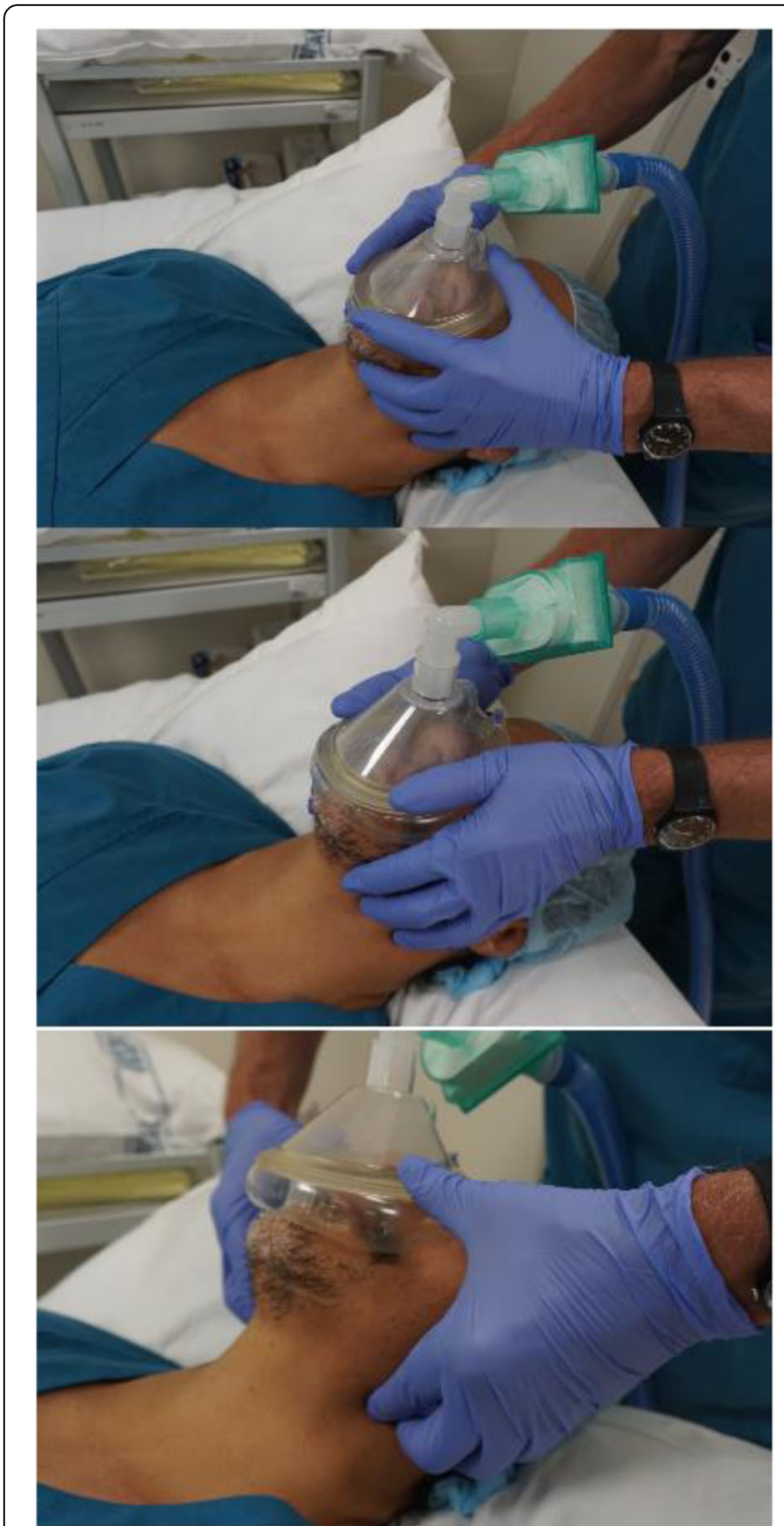

Fig. 1 Two-handed positions for face mask ventilation. From top to bottom: double CE-grip, thenar eminence and transverse mandibular techniques

It is important that one uses a technique that he or she is comfortable with. Whatever the primary FMV technique, tiring practitioners might want to alternate or combine techniques. We would suggest that practitioners consider the technique advocated in this correspondence as they may find it useful in difficult FMV contexts.

\section{Abbreviation}

FMV: Facemask ventilation

\section{Authors' contributions}

All authors have made material contributions to this manuscript. Francois Lemay and Jeremy Cooper both equally helped research the literature and write and review the manuscript. All authors read and approved the final manuscript.

\section{Authors' information}

None.

\section{Funding}

None.

\section{Availability of data and materials Not applicable.}

\section{Ethics approval and consent to participate} Not applicable.

\section{Consent for publication}

Written consent has been obtained for images provided by the theatre staff involved in Fig. 1.

\section{Competing interests \\ None.}

\section{Author details}

'Département d'anesthésiologie et de soins intensifs, Université Laval, Québec, Canada. ${ }^{2}$ Centre Hospitalier Universitaire de Québec, Hôtel-Dieu de Québec, Québec, Canada. ${ }^{3}$ Green Lane Department of Cardiothoracic and ORL Anaesthesia, Auckland City Hospital, Auckland, New Zealand.

Received: 8 May 2020 Accepted: 18 May 2020

Published online: 26 May 2020

\section{References}

1. Cook TM, El-Boghdadly K, McGuire B, McNarry AF, Patel A, Higgs A. Consensus guidelines for managing the airway in patients with COVID-19. Anaesthesia. 2020:1-20. https://doi.org/10.1111/anae.15054.

2. Frerk C, Mitchell VS, McNarry AF, Mendonca C, Bhagrath $R$, Patel A, et al. Difficult Airway Society 2015 guidelines for management of unanticipated difficult intubation in adults. Br J Anaesth. 2015;115(6):827-48.

3. Apfelbaum JL, Hagberg CA, Caplan RA, Blitt, Casey D. Practice guidelines for management of the difficult airway an updated report by the American Society of Anesthesiologists Task Force on Management of the Difficult Airway. Anesthesiology. 2013;118(2):1-20.

4. Fei M, Blair JL, Rice MJ, et al. Comparison of effectiveness of two commonly used two-handed mask ventilation techniques on unconscious apnoeic obese adults. Br J Anaesth. 2017;118(4):618-24.

5. Jung M-C, Hallbeck MS. The effect of wrist position, angular velocity, and exertion direction on simultaneous maximal grip force and wrist torque under the isokinetic conditions. Int J Ind Ergon. 2002;29(3):133-43.

\section{Publisher's Note}

Springer Nature remains neutral with regard to jurisdictional claims in published maps and institutional affiliations.

\section{Acknowledgements}

None. 